Supplement of Nat. Hazards Earth Syst. Sci., 20, 2335-2349, 2020

https://doi.org/10.5194/nhess-20-2335-2020-supplement

(c) Author(s) 2020. This work is distributed under

the Creative Commons Attribution 4.0 License.

(c) (1)

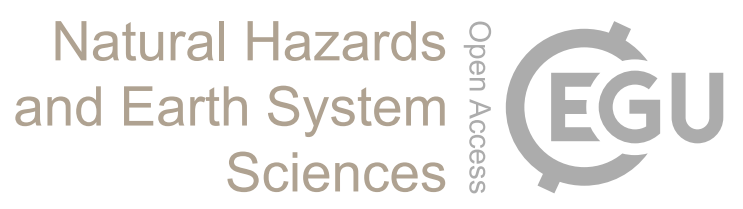

Supplement of

\title{
Lagrangian modelling of a person lost at sea during the Adriatic scirocco storm of 29 October 2018
}

\section{Matjaž Ličer et al.}

Correspondence to: Matjaž Ličer (matjaz.licer@nib.si)

The copyright of individual parts of the supplement might differ from the CC BY 4.0 License. 


\section{Backtracking from the beaching location with both HF radar and NEMO currents}

2 These simulations were performed as described in the body of the paper, Section 4.1. The result is shown on Figure 1 below

3 - left column depicts HF radar backpropagation, right column depicts NEMO backpropagation. During the final hours of the

4 drift, NEMO currents seem to advect substantially differently (and attain less spatial distance from the beaching location) than

5 the observed currents - hence the difference between the two "final" positions (locations of the red circles in Figure 1).

\section{BACK TRACKING WITH \\ WERA CURRENTS}
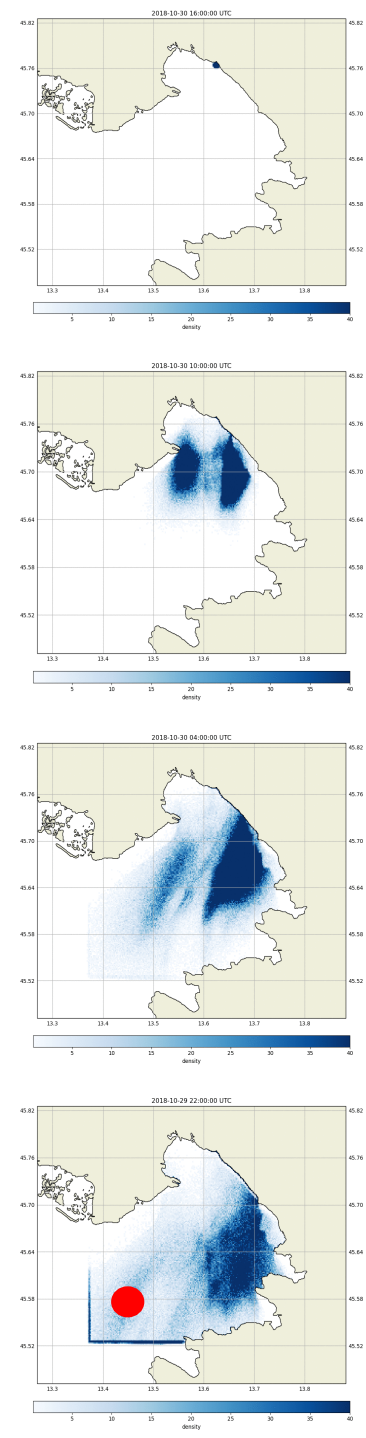

\section{BACK TRACKING}

WITH

NEMO CURRENTS
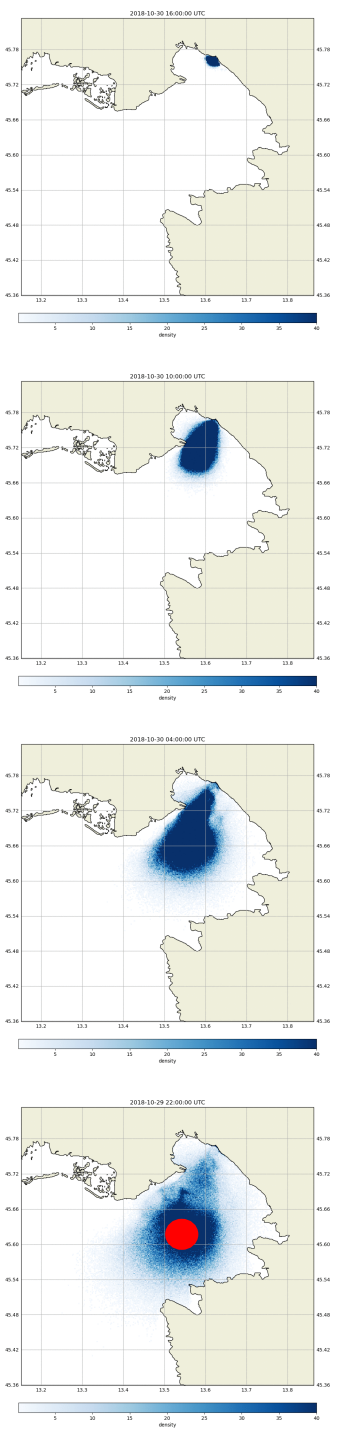

Figure 1. Back-propagation with HF and NEMO currents. Left: HF radar backpropagation. Right: NEMO backpropagation. 


\section{Forward tracking from the beaching location with both HF radar and NEMO currents}

7 As pointed out in the paper, HF radar observational domain is limited in space. The accident occurred well outside the obser8 vational domain. Therefore we cannot use HF surface currents, as they are, to perform a forward tracking simulation of the 9 entire drift. We can however attempt to perform such a simulation if we extrapolate the HF surface current field beyond its observational domain. While this is not entirely unproblematic, one can reasonably expect that such an extrapolation would be less questionable during a Scirocco than during any Bora episode. The reason for this distinction is that during the Scirocco the dominant surface currents along the northern Istrian coast flow northward, similarly as in the southern part of the mouth of the Gulf of Trieste. During Bora, the circulation in the southern part of the mouth of the Gulf can be however very different from the circulation along the northern Istrian coast. Southern part of the Gulf of Trieste during Bora typically exhibits a pronounced zonal flow while the circulation along the northern Istrian shore tends to be meridional due to the formation of a Bora driven double gyre system.

We have therefore performed a nearest-neighbor extrapolation of the WERA HF surface currents during the period of the drift. We have thus extended the HF surface current field to include the entire region of the drift. We have, to be clear, thus introduced the error which lies in the assumption that the currents in the vicinity of the accident are similar to those at the closest point of the radar observational domain. We then used this extrapolated field to perform forward tracking simulation of the Person with surfboard object type. The result is presented in Figure 2 below.

It is interesting to note that NEMO and HF currents tend to advect quite similarly until the final hours of the drift. The lag between the NEMO and the HF advected particles seems to be accumulated mostly in the last hours of the drift (again, the red circles in Figure 2). 

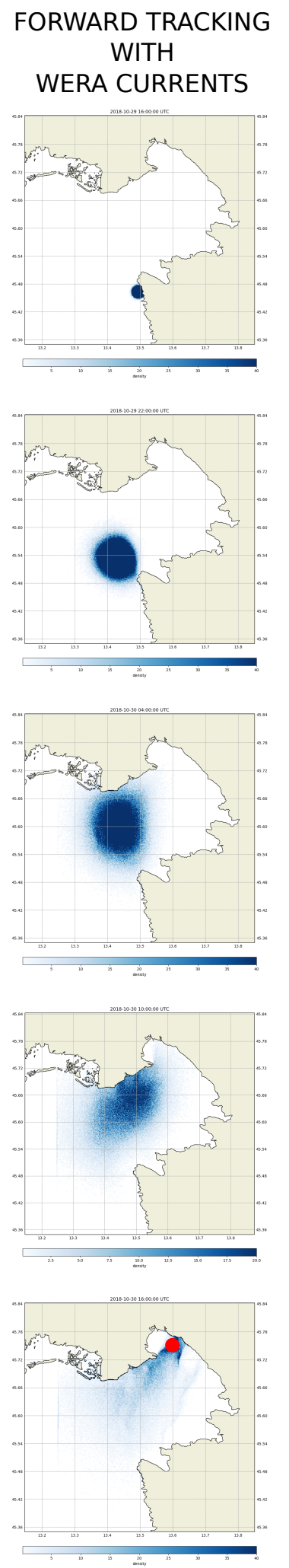

FORWARD TRACKING

WITH

NEMO CURRENTS
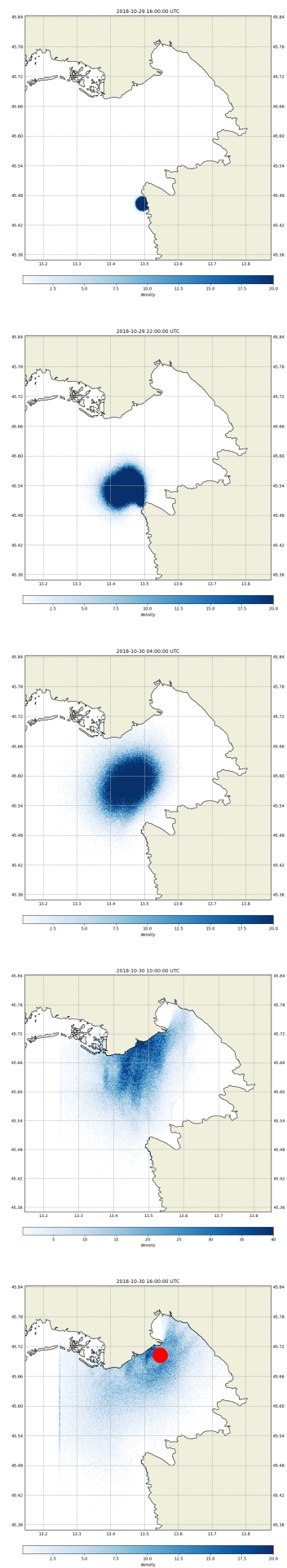

Figure 2. Forward propagation with HF and NEMO currents. Left: HF radar forward propagation. Right: NEMO forward propagation. 